\title{
Crenças de Educadoras de Creche Sobre Temperamento e Desenvolvimento de Bebês ${ }^{1}$
}

\author{
Lígia Ebner Melchiori ${ }^{2}$ \\ Universidade Estadual Paulista, Bauru \\ Zélia Maria Mendes Biasoli Alves \\ Universidade de São Paulo, Ribeirão Preto
}

\begin{abstract}
RESUMO - O objetivo desta investigação foi verificar o julgamento de educadoras de creche sobre os fatores que causam e/ou influenciam o temperamento e o desempenho de bebês. Vinte e uma educadoras foram entrevistadas a respeito de cada um dos 90 bebês de 4 a 24 meses sob seus cuidados, seguindo um roteiro semi-estruturado. Os resultados mostram que (a) as crenças das educadoras são predominantemente ambientalistas, isto é, que as educadoras atribuem influência significativa do ambiente no temperamento e desempenho dos bebês, e (b) que elas subestimam o seu papel de promotoras do desenvolvimento das crianças. A necessidade de se conhecer as crenças das educadoras para a eleboração de programas de treinamento eficazes é enfatizada.
\end{abstract}

Palavras-chave: crenças; educadoras; creche; desenvolvimento infantil; temperamento.

\section{Beliefs of Day Care Centers' Caretakers About Babies' Temperament and Development}

\begin{abstract}
This article aims at describing the judgement of day care centers' caretakers about factors that cause or influence the babies' temperament and performance. Twenty-one caretakers were interviewed about each of the ninety babies under their care, who were 4 to 24 months old, using a semi-structured guide. The results show that the caretakers' beliefs are predominantly environmental, i.e., they attribute significant influence of the environment upon the babies' temperament and performance. They also underestimate their role as promoters of child development. It is argued for the necessity of having a deeper understanding of caretakers' beliefs in order to develop efficient training programmes for them.
\end{abstract}

Key words: beliefs; educators; daycare center; child development; temperament.

O papel da crença e sua importância, particularmente para o comportamento dos pais, vem sendo extensamente pesquisado (Goodnow \& Collins, 1990; Harkness \& Super, 1996; Sigel, McGullicuddy-DeLisi \& Goodnow, 1992). Alguns autores como D‘Andrade (1987) e Harkness e Super (1996) salientam que as crenças subsidiam o comportamento do indivíduo, que elas são mais implícitas que explícitas e que estão ligadas ao comportamento mesmo sem a mediação de se decidir fazê-lo conscientemente. Goodnow (1992) sumariza quatro razões para se estudar e aprofundar o conhecimento das crenças parentais: (a) elas são uma interessante forma de cognição e desenvolvimento do adulto, (b) mostram um caminho para ajudar a compreender as ações dos pais, (c) são aspectos do contexto no qual a criança vive e (d) podem indicar direções nos processos de transmissão e mudança cultural.

A utilização do termo "crença" é controversa. Por exemplo, Goodnow e Collins (1990) rejeitam a expressão "sistemas de crença", preferindo o termo "idéias", embora, ocasionalmente, utilizem o termo "cognição" ou "expectativas". Esses autores ressaltam que "idéias" não tem uma conotação

1 Este trabalho é derivado da tese de Doutorado da primeira autora, sob orientação da segunda. As autoras agradecem o apoio concedido pela FAPESP.

2 Endereço: Unesp-Bauru, Departamento de Psicologia, Av. Engenheiro Luís Edmundo Carrijo Coube $\mathrm{s} / \mathrm{n}^{\circ}$, Bairro Vargem Limpa. CEP.: 17033-360 - Bauru-SP. E-mail: imelch@terra.com.br de "inércia", ao contrário, transmite a noção de ação e algum grau de sentimento. Já Harkness e Super (1996) preferem o termo "etnoteoria", apesar de fazerem uso de "sistema cultural de crença" no próprio título do livro do qual são organizadores, arguindo que este é mais facilmente identificado pelos leitores. Palacios (1990), por sua vez, refere-se a "processos cognitivos", "crenças" e "idéias" indistintamente. Contudo, há quem enfatize, como Bastos (1991), a necessidade de uma análise conceitual desses termos para uma designação mais precisa dos fenômenos aos quais eles se referem.

Independentemente das diferentes designações, há consenso quanto ao fato de que o comportamento dos pais não consiste de uma série de respostas acidentais ao comportamento de seus filhos. Eles têm noções ou idéias a respeito de como devem tratar seus filhos, isto é, com base no que acreditam ser bom ou ruim, naquilo que eles valorizam ou desvalorizam, e que norteiam a sua prática na relação com os filhos. Partindo do princípio que os pais agem com seus filhos em função de crenças desenvolvidas através das vivências e experiências sociais e culturais ao longo de suas vidas, pode-se concluir que as educadoras de creche também agem com os bebês em função de suas idéias e expectativas a respeito de desenvolvimento, adquiridas ao longo do tempo.

A escassez de estudos a respeito das crenças parentais e de educadores, ao invés de ser considerada limitadora, deveria ser vista como um grande desafio. Alguns dos trabalhos que mais se destacam nessa área (Hess, Kashiwagi, Azuma, Price 
\& Dickson, 1980; Holloway \& Reichhart-Erickson, 1989) referem-se ao levantamento das idades em que os pais e/ou educadores julgam que bebês e crianças são capazes de emitir comportamentos ou desenvolver habilidades que lhe são peculiares. Os estudos são variados, incluindo desde aqueles que buscam investigar as idéias sobre quando o bebê deve começar a sentar e engatinhar e avaliar as habilidades como auto-alimentar-se e vestir-se, até julgamentos sobre comportamentos de assertividade verbal, maturidade emocional e independência.

Outro tema investigado é se a diferença no comportamento das crianças é o resultado ou a causa das expectativas a respeito de seu desenvolvimento. Miller (1988) e Goodnow e Collins (1990) afirmam que as expectativas precoces dos adultos tendem a pressionar as crianças em direção à emissão precoce de alguns comportamentos, uma vez que há mais estimulação e atenção. Edwards, Gandini e Giovaninni (1996), investigando essa questão com educadores de creche e professores de pré-escola, levantaram a hipótese de que as expectativas são a causa e o efeito do comportamento das crianças, uma vez que estas não só influenciam como são influenciadas. Esse estudo reforça a idéia da influência recíproca e bidirecional entre pais e filhos, educadores e crianças.

Lordelo (1995), Oliveira (1995) e Vasconcellos e Valsiner (1995) têm salientado a importância da abordagem sóciointeracionista de desenvolvimento ao se trabalhar com crianças, analisando o desenvolvimento como produto da interação indivíduo-ambiente. O desenvolvimento vai então se construindo na e pela interação dos bebês com outras pessoas do meio, principalmente por aquelas mais envolvidas com eles, de forma afetiva e efetiva (Oliveira, Mello, Vitória \& Rossetti-Ferreira, 1993).

Com o objetivo de determinar a distância das crenças paternas e profissionais a respeito do desenvolvimento da criança, Edwards e cols. (1996) aplicaram um questionário em 240 pais/educadores norte-americanos e italianos. Eles concluíram que as mães e os pais têm expectativas similares sobre o desenvolvimento dos filhos; no entanto, guardam grandes diferenças em função da cultura: pais norte-americanos têm expectativas sociais mais precocemente que os italianos. Quanto aos professores e educadores dos dois países, não houve diferença na maioria das expectativas focalizadas. $\mathrm{O}$ dado que merece ser enfatizado é que os educadores de creche, da mesma forma que os professores da préescola, responderam de forma mais precisa às questões referentes às crianças da faixa etária com que trabalhavam. Os autores concluem que esses profissionais têm expectativas que em parte refletem suas tradições culturais e ideologias sociais e, por outro lado, o tipo de cultura compartilhada internacionalmente com outros profissionais de educação, com treinamento e experiência com crianças equivalentes. Portanto, o nível educacional é uma variável importante na determinação das crenças.

Em um estudo com 139 casais, Palacios (1990) encontrou três classes de pais: os modernos, os tradicionais e os paradoxais. Os modernos acreditam que as diferenças individuais resultam da interação entre fatores hereditários e ambientais; suas expectativas sobre desenvolvimento são otimistas e acreditam que influenciam seus filhos em características que estes ainda vão adquirir. Em geral, esses pais têm um alto nível educacional, profissional e vivem em cidades. Os tradicionais revelam idéias inatistas e se vêem quase incapazes de influenciar o desenvolvimento de seus filhos, são a favor de práticas educacionais coercitivas e têm pouca predisposição para interações com seus filhos. O nível educacional deles é baixo, geralmente habitam ou vieram de ambientes rurais. Os pais classificados como paradoxais são ambientalistas, têm expectativas otimistas a respeito do desenvolvimento precoce dos filhos, embora estas não os levem a interagir com eles mais cedo. Predominam, entre esses pais, os níveis educacionais médio e baixo.

Becker (2001) realizou um importante estudo visando justamente analisar qual era a epistemologia subjacente ao trabalho do professor, da pré-escola ao terceiro grau, e concluiu que o professor pode manifestar-se predominantemente ambientalista, inatista em alguns casos, ou ainda interacionista. No entanto, mesmo os professores com posições inatistas ou próximas da interacionista não conseguem superar totalmente sua epistemologia empirista, talvez por ser a que mais se aproxima do senso comum, segundo Becker. Esse autor enfatiza que "a superação da escola atual, na direção de uma escola verdadeiramente democrática... implicará, necessariamente, esta crítica" (p. 28).

Conhecer as crenças das educadoras a respeito de temperamento e desempenho de bebês sob seus cuidados pode fornecer subsídios importantes para se trabalhar a sua formação. Pesquisadores como Amorim e Rossetti-Ferreira (1999) ressaltam que uma das questões de grande relevância em relação à educação infantil tem sido a definição do perfil do educador e a sua formação inicial e continuada. Em relação a esse último aspecto, Pantoni, Teles, Mello e Rossetti-Ferreira (1998) ressaltam que:

A formação continuada deve considerar o educador como um ser total. Sua identidade profissional está associada à identidade pessoal. São partes da mesma coisa. É importante, então, prestar atenção às concepções, crenças, valores e projetos de vida desse profissional. Muitos deles não aparecem claramente durante o processo de formação. Porém, refletem-se na atuação desse profissional, influenciando a qualidade geral de seu trabalho. (p. 26)

As educadoras de creche passam de quatro a dez horas diárias com os bebês; portanto, identificar e analisar quais são suas crenças a respeito do temperamento e do desempenho deles é de extrema relevância, pois, por mais que sejam tecnicamente orientadas em como lidar com bebês, as crenças subjacentes vão influenciar diretamente a sua maneira de agir e a qualidade geral de seu trabalho. É claro que uma formação continuada pode alterar o sistema de crenças; no entanto, para modificá-lo, faz-se necessário conhecê-lo.

Um outro aspecto que vem sendo discutido na literatura (Haddad, 1991; Martinez, 1998; Vitória, 1997) é de como as educadoras julgam as mães das crianças que freqüentam creches e escolinhas maternais. Martinez (1998), analisando 
como vem se caracterizando o ingresso da criança pequena na escola, concluiu que as educadoras julgam que esse processo depende das condições emocionais da mãe, de sua insegurança e desconfiança na escola, os quais influenciam, de forma negativa, a adaptação inicial da criança ao ambiente coletivo.

Haddad (1991) analisa as queixas das educadoras de creche em relação à figura materna e sua falta de atenção para com os próprios filhos e com o trabalho da creche. Tanto Haddad quanto Vitória (1997) encontraram uma percepção depreciadora da mãe por parte das educadoras, como pessoa pouco atenciosa e colaboradora com o filho. A esse respeito, Vitória salienta que, de certo modo, a creche está se apresentando

na contramão do processo social que vem se desenvolvendo, caracterizado pelo acirramento da privacidade, da ambição profissional, da conquista de condições materiais mais confortáveis e sofisticadas, enquanto que ela tende a promover o sentido de coletividade, relacionamentos, afetos e da coisa pública. (p. 101)

Essa visão pode ser explicada não só pelo papel histórico da mãe, desenvolvido culturalmente desde o século XVIII, como a principal provedora do cuidado e educação infantil, como também pelo papel da criança como sendo o centro monopolizador da sociedade (Ariés, 1981). Apesar das profundas mudanças ocorridas nos papéis desempenhados pelos homens e mulheres, na segunda metade do nosso século, constata-se que "as representações sobre maternidade e/ou função materna parecem se mostrar persistentes no tempo e em diferentes regiões de cultura ocidental" (Vitória, 1997, p. 105). Para essa autora, o fato de as educadoras perceberem o quanto o papel que elas próprias desempenham é pouco reconhecido e valorizado na sociedade pode levá-las a uma depreciação irracional da figura materna, como uma tentativa de autocompensação. Trata-se, portanto, de outra possibilidade de explicação da depreciação das mães por parte das educadoras

Neste trabalho, pretendemos responder algumas questões específicas do sistema de crenças das educadoras, que dizem respeito ao desempenho e temperamento dos bebês sob seus cuidados, a saber: (a) qual é a epistemologia subjacente à prática das educadoras? (b) quem são as pessoas dos ambientes familiar e coletivo que as educadoras julgam ter influência no temperamento e desempenho dos bebês? (c) em que direção elas julgam que essa influência ocorre, isto é, de forma a favorecer ou prejudicar o desenvolvimento infantil? (d) as mães são também julgadas de forma depreciativa pelas educadoras? (e) como as educadoras percebem seu próprio papel no desenvolvimento dos bebês?

\section{Método}

\section{Amostra}

Colaboraram para a realização desse estudo 21 educadoras de creche, do sexo feminino, com idades variando de 21 a 57 anos, tendo entre três a 18 anos de experiência no cuidado de bebês, na instituição em que os dados foram coletados. Vinte e quatro porcento das educadoras possuíam o primeiro grau completo, $57 \%$ o segundo grau completo e o restante (19\%), o segundo grau incompleto. Elas cuidavam de 90 bebês de quatro a 24 meses, sendo $49 \%$ do sexo feminino e $51 \%$ do sexo masculino, todos filhos de funcionárias de um hospital universitário, com nível de escolaridade variando do primeiro grau ao superior. A profissão das mães incluía desde faxineira até médicas e administradoras.

\section{Procedimento}

Foi elaborado um roteiro para entrevista semi-estruturada, solicitando que os educadores descrevessem o comportamento de cada bebê durante o período em que ele se encontrava na creche, incluindo: (a) a chegada - quando o bebê era trazido pela mãe, pai ou ambos; (b) a alimentação - mamadeira ou seio, suco, fruta, refeições; (c) o processo de higienização - troca de fraldas e banho; (d) a saída da creche. Além destes aspectos foram descritos: (a) o temperamento dos bebês manifestos durante todo o dia e em situações específicas; (b) suas competências nas áreas: motora, social, cognitiva e linguagem; (c) como o educador interpretava o comportamento, o temperamento e a competência de cada bebê sob seus cuidados.

Os educadores foram entrevistados na própria creche, durante o período de trabalho e, em cada entrevista, eram solicitados a focalizar um bebê de cada vez, dentre os 4 ou 5 sob seus cuidados mais diretos. Foram realizadas 90 entrevistas com as 21 educadoras, com a duração média de meia hora, totalizando 45 horas de gravação em áudio.

\section{Análise dos dados}

As entrevistas foram transcritas na íntegra e, em seguida, foi elaborado um sistema de categorias de crenças com base na abordagem de desenvolvimento que as educadoras estavam usando para interpretar o temperamento e o desempenho dos bebês. O sistema obedeceu aos seguintes critérios: exaustividade, exclusividade, nível de amplitude das categorias e nível de inferência das categorias (Sigolo \& Biasoli-Alves, 1998). Foram encontrados, na fala das educadoras, três tipos de categorias de crenças:

1. INATISTA - quando a verbalização das educadoras tinha como foco principal a influência de uma variável biológica ou genética (Ex: "O DNA dele deve ser de calmaria”), incluindo a noção de que havia estágios de maturação pré-programados (Ex: "Quando a criança é brava de gritar assim aí melhora no Berçário 3 porque lá ele já começa a brincar, andar, já consegue fazê o que qué, já não chora muito") ou fatores não explicitados (Ex: "A criança já nasce assim”).

2. AMBIENTALISTA - quando a verbalização dos educadores tinha como principal foco a influência das variáveis ambientais como determinantes do temperamento ou desempenho dos bebês (Ex: "Se o pai e a mãe é as- 
sim bem extrovertido, então isso influi"; "A estimulação que é dada pra eles, o carinho, a presença de brinquedos").

3. INTERACIONISTA - quando a verbalização das educadoras tinha como principal foco a influência da interação entre as variáveis ambientais e as biológicas/ genéticas (Ex: "Eu acho que um pouco já é da criança, já nasce com ela, mas acho que influencia o ambiente em casa, como a mãe trata, o ambiente aqui [na creche], eu acho que tudo isso influencia a criança").

4. OUTRAS - esta quarta categoria foi estabelecida para o caso de não se poder decidir a qual das categorias acima citadas pertencia a verbalização dos educadores (Ex: "Aquele que não dorme quase nada é uma criança muito irritada, chora demais").

\section{Resultados}

Foram obtidas 119 respostas classificadas como indicações de crenças a respeito da origem do temperamento dos bebês e 201 como indicações de crenças de desempenho. Para o temperamento e o desempenho dos bebês, nas quatro categorias descritas, considerou-se como $100 \%$ o total das respostas emitidas sobre o temperamento e como $100 \%$ o total das respostas emitidas sobre o desempenho dos bebês. A Figura 1 mostra que as respostas foram categorizadas, principalmente, em torno de duas abordagens conceituais de desenvolvimento, a Inatista e a Ambientalista, com predomínio da segunda. É importante acrescentar que há educadoras que exprimem, em sua fala, ambos os tipos de crenças, isto é, ora inatistas, ora ambientalistas, embora nenhuma delas tenha emitido apenas crenças interacionistas.

As educadoras que enfatizam o meio ambiente (Abordagens Ambientalista e Interacionista) julgam que diferentes pessoas influenciam o desenvolvimento dos bebês. A Figura 2 mostra quem são as pessoas do ambiente que elas julgam exercerem influência no temperamento e desempenho dos bebês.

A mãe é considerada a principal fonte de influência no temperamento dos bebês, seguida pelo pai. Apenas 7\% e 5\%

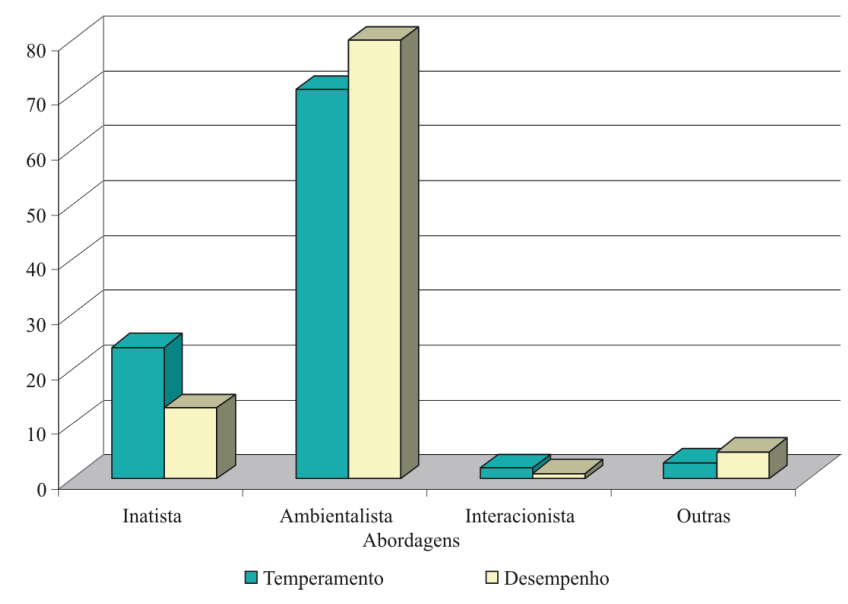

Figura 1. Percentual de categorias de crenças das educadoras sobre temperamento e desempenho de bebês.

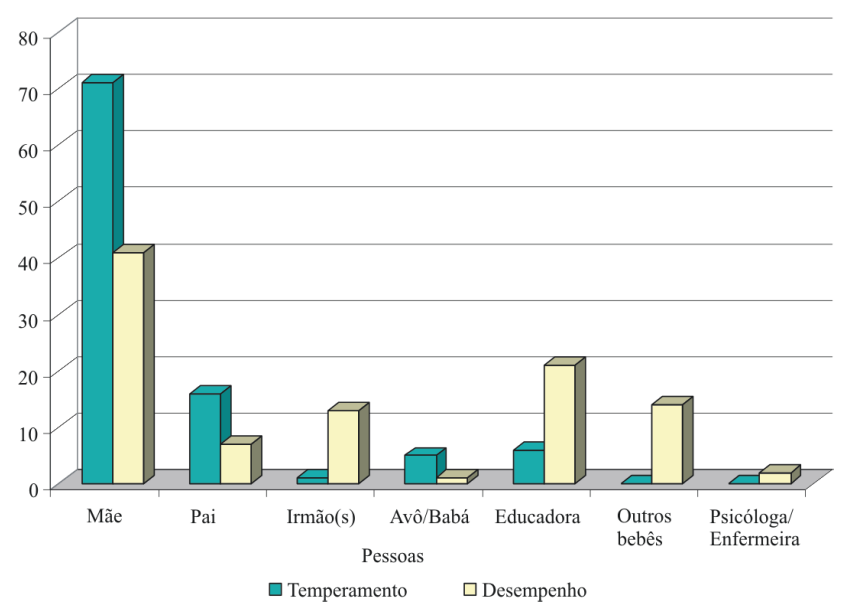

Figura 2. Percentual de agentes dos ambientes familiar e coletivo percebidos pelas educadoras como influenciando no temperamento e desempenho de bebês. O percentual foi calculado com base no total de respostas categorizadas nas abordagens ambientalista e interacionista, para cada variável (temperamento e desempenho), separadamente.

das respostas referem-se, respectivamente, às influências da educadora e da avó/babá. A mãe também é percebida pelas educadoras como a principal responsável pelo desempenho dos bebês mas, nesse aspecto, mais pessoas são percebidas como influenciando: as próprias educadoras, outros bebês da creche, irmãos, pais e algumas outras pessoas que frequientam a creche ou a casa da família. Nesse caso, a influência das educadoras é vista como maior que a paterna.

Com base nas pessoas do ambiente que influenciam o desenvolvimento dos bebês, indicadas em pelo menos 5\% das respostas das educadoras, verificou-se a direção que essa influência era julgada: se positiva ou negativa. Considerouse como $100 \%$ o total de respostas específicas para cada um dos agentes dos ambientes familiar e coletivo, isto é, considerou-se o total de indicativos de que a figura materna, por exemplo, exercia influência sobre o temperamento do bebê, e calculou-se o percentual dessas respostas no sentido de favorecer ou prejudicar o desenvolvimento. O mesmo ocorreu em relação ao desempenho dos bebês. Na Figura 3, podese observar o julgamento das educadoras sobre a influência positiva ou negativa no temperamento dos bebês, exercida pelas pessoas que foram indicadas em pelo menos $5 \%$ das respostas.

Em relação ao temperamento dos bebês, as educadoras julgam a sua influência sempre positiva e a do pai quase sempre positiva, embora os motivos apontados sejam diversos. As educadoras, pela forma de agirem com os bebês (Ex: "Eu acho que ela se solta porque a gente tenta fazer o máximo pra agradar ela, pra ver se ela muda e a gente tem notado progresso nela, porque agora ela tá sorrindo mais, já tá dançando, a gente chama, mexe com ela, joga beijo, ela já fica sorrindo"). Já a figura paterna, por características pessoais (Ex: "...ele é um menino bem alegre, eu acho que puxou pro pai dele, o pai dele é bem alegre, eu acho assim”).

A mãe é percebida como influenciando de forma positiva, em pouco mais da metade das respostas, e influenciando de forma negativa, em quase $50 \%$ delas. Ela é vista como 


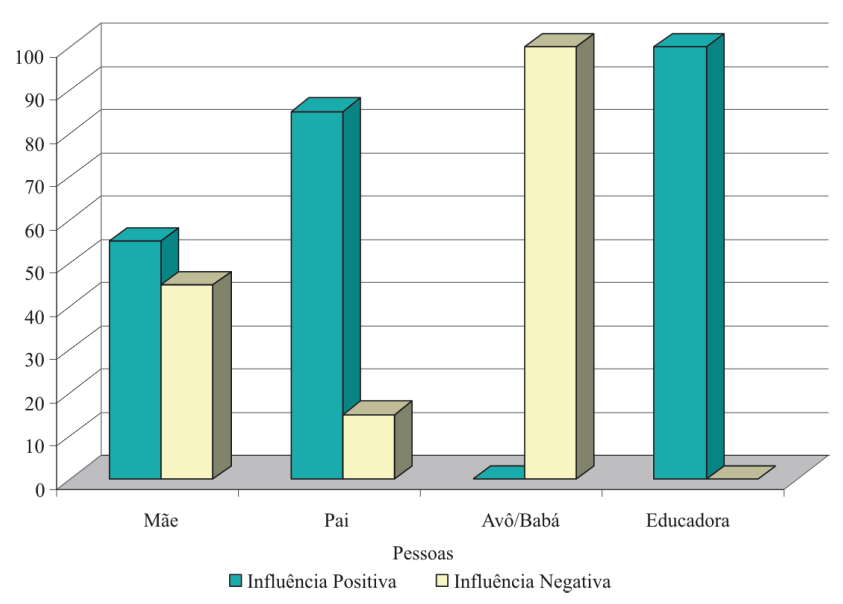

Figura 3. Percentual de julgamentos das educadoras a respeito de agentes dos ambientes familiar e coletivo que exercem influência positiva ou negativa no temperamento dos bebês.

influenciando positivamente por suas características pessoais (Ex: "Talvez seja o modo como a mãe também é, como se apresenta né, é uma moça bem alegre, risonha, bem falante né, é uma moça que passa toda essa alegria pra criança”); pelo seu comportamento (Ex: "Eu tenho a impressão que a mãe dela deve ser uma pessoa assim de dar muita atenção pros filhos, pelo menos me passa essa imagem”); pela ordem de nascimento do bebê na família (Ex: "No segundo filho a gente tá mais calma, aceita mais as coisas de vim pra creche, ficar longe da criança; entra mais calma a criança [na creche], a gente nota isso nas mães de segundo filho, então elas [mães] já não choram”).

Segundo as educadoras, a mãe exerce influência negativa devido, também, às suas características pessoais (Ex: "Porque a mãe dela também não é dada, você entendeu? Parece que ela é fechada, então eu acredito assim que ela [bebê] também puxou pra mãe nesse sentido né, porque ela fica mais com a mãe do que aqui na creche, ela falta muito"); ao seu comportamento (Ex: "A mãe que não dá carinho à criança é mais triste né, mais apagada”); aos problemas que enfrenta (Ex: "Os problemas que a mãe tem passa pros filhos, quer queira quer não”); pela insegurança no trato do primeiro filho (Ex: "O primeiro filho quando a gente tem, a gente fica insegura, passa muita insegurança pra eles, então eu acho que é isso") ou pelo pouco tempo que os pais ficam com o bebê (Ex: "É, eu acho que essa agitação é porque ele é muito carente, porque ele fica muito tempo aqui, em casa eles vão dormir, porque se ele dorme aqui depois do almoço, não dorme mais, a hora que vai embora seis, seis e pouco, provavelmente ele chega em casa e vai dormir, levanta de manhã e já vem pra cá, então ele não tem contato com os pais em casa”).

Por outro lado, as avós e babás foram julgadas como exercendo apenas influência negativa sobre o temperamento dos bebês, pelo excesso de cuidados com eles (Ex: “...e tem essa moça que cuida dele e tal né, eu acho que essa é a parte que ele fica enjoado, não sou contra esse tipo, mas acaba deixando a criança assim enjoadinha, porque é qua- se aquela coisa né de ficar em casa, faz isso, faz aquilo, faz tudo que ele quer").

$\mathrm{Na}$ Figura 4, pode-se observar o julgamento das educadoras sobre a influência positiva ou negativa no desempenho dos bebês, exercida pelas pessoas que obtiveram um percentual de influência sobre os bebês igual ou superior a $5 \%$.

As figuras paterna e da educadora, bem como a presença de irmão(s) ou de outros bebês no ambiente coletivo são vistas como influenciando de forma positiva, sempre ou quase sempre. O pai, pelo modo de lidar com o filho e por características pessoais (Ex: “...é um pai que demonstra muito carinho, eu acho que é isso que deixa ele [bebê] desse jeito [bebê alegre, tranqüilo]”; “O pai é bem calmo”). A presença dos irmãos e outros bebês, pela estimulação que estes proporcionam (Ex: "Então eu falo assim, quem tem irmão já tem escola, é muito difícil ser mais quietinho, o irmão pega fogo e a criança vai no mesmo embalo, então, ele tem irmãozinho”). As educadoras, também pela estimulação que proporcionam (Ex: "é a estimulação que a gente faz pra eles, isso ajuda, quanto mais estimulação melhor"), incluindo colocar o bebê no chão (Ex: "Eu acredito que colocando a criança no chão ela desenvolve mais, percebe mais, brinca mais, porque ela, por exemplo, no carrinho, ela só aceita o que lhe oferece né, a gente mostra o brinquedinho ela olha, brinca, põe na mãozinha, às vezes deixa cair no chão, ela não poder pegar né, agora, no chão ela se esparrama, se desenvolve melhor").

As mães são percebidas como influenciando o desenvolvimento dos filhos de forma negativa, em quase $50 \%$ das respostas, devido ao excesso de atenção dada ao filho (Ex: "Na verdade eu acho que o que atrapalha muito ela [criança] de uma maneira geral, é o comportamento da mãe, aquela obsessão da mãe, aquela coisa de cercar ela muito né, de achar que ela não cresceu, aquelas coisas, eu acho que atrapalha”) ou, ao contrário, à falta de atenção e de envolvimento com o filho(a) (Ex: "Falta de incentivo dela que ele é assim, falta a mãe fazer a parte dela"; "Eu acho a mãe muito des-

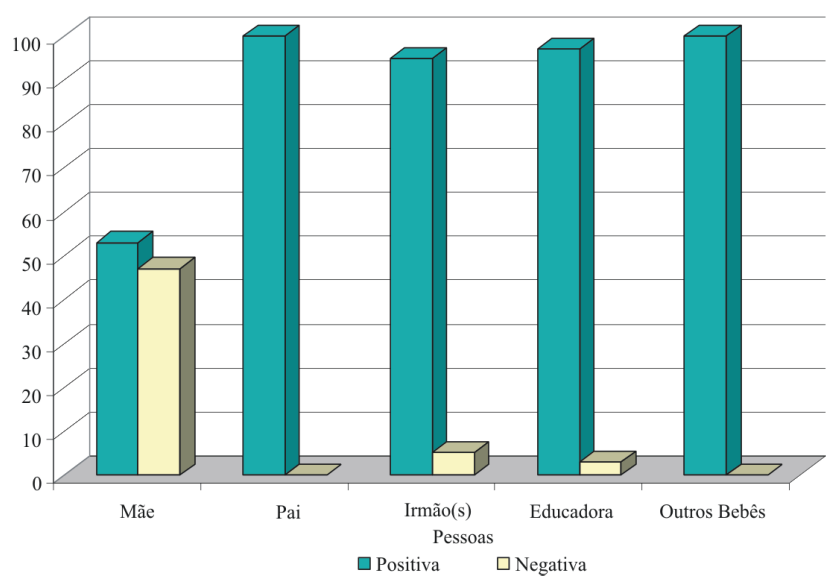

Figura 4. Percentual de julgamentos das educadoras a respeito de agentes dos ambientes familiar e coletivo que exercem influência positiva ou negativa no desempenho dos bebês. 
ligada, a mãe não liga, não é aquela mãe que chega e fala, não te pergunta nada, chega, pega, porque a gente anota tudo né, muitas mães perguntam, a gente comenta, ela não, eu acho que um pouco tá ligado a isso"). Ela é vista como influenciando de forma positiva, em função do seu comportamento (Ex: "Ele deve ficar no chão, do jeito que a mãe dele é, ela é bem solta em relação ao M.”); de sua segurança (Ex: "Às vezes ele [bebê] tá doente e ela não desespera, não enlouquece, ela leva no médico e fala: - 'Tem remédio'”); do envolvimento com a criança (Ex: "E ela se importa muito com eles, com os dois [bebê e irmão] porque se eles têm algum problema ela pega o filho dela, passa pelo médico e vai embora, então ela dá muito valor: 'Se meu filho não tá bem eu tô saindo, numa boa',') e por características pessoais (Ex: “A mãe dele é uma pessoa muito calma sabe...").

Em síntese, (a) houve predominância das respostas das educadoras que enfatizam o meio ambiente como exercendo influência no temperamento e no desempenho dos bebês; (b) a mãe é percebida pelas educadoras como sendo quem mais influencia no temperamento e no desempenho de seus filhos; no entanto, essa influência é vista como positiva apenas em pouco mais da metade das respostas; (c) o pai é percebido como a pessoa que mais influencia no temperamento dos bebês depois da mãe, e é julgado pelas educadoras como exercendo influência positiva, na maior parte das respostas; (d) apesar da figura paterna ser julgada como exercendo pouca influência no desempenho dos bebês, essa influência é considerada sempre positiva pelas educadoras; (e) as educadoras julgam exercer pouca influência no temperamento dos bebês ( $7 \%$ das respostas) e acreditam também que a influência sempre é positiva ou próxima a isso; (f) avós e babás são julgadas como exercendo mais influência no temperamento que no desempenho dos bebês, mas essa influência é considerada negativa; ( $\mathrm{g}$ ) outros bebês da creche e os irmãos são julgados como exercendo influência $100 \%$ positiva no desempenho dos bebês ou quase sempre positiva, respectivamente.

\section{Discussão}

Esse estudo partiu do pressuposto de que, para se trabalhar com educadoras de creche, é necessário conhecer seu sistema de crenças, que tem uma base histórica que pode variar conforme as condições de vida das pessoas e seu acesso ao conhecimento (Lordelo, Fonseca \& Araújo, 2000; Palacios, 1990; Vigotsky, 1978). Infere-se, também, que as crenças funcionam de forma semelhante às expectativas em outros domínios, como as "profecias auto-realizadoras" (Rosenthal \& Jacobson, 1968a, 1968b); que o que elas acreditam como determinantes do desempenho ou do temperamento dos bebês influa na sua ação.

Os dados a respeito das crenças sobre temperamento e desempenho dos bebês deste estudo indicam a predominância de crenças Ambientalistas. Em outros termos, o estímulo e a conseqüência vêm de fora da criança e são os responsáveis pela aquisição, manutenção ou extinção de formas específicas de ação. Nessa abordagem, a criança é vista como sendo passível de ser moldada e influenciada integralmente pelo meio, não contribuindo ativamente para o seu próprio desenvolvimento nem atuando sobre o meio ambiente. Oliveira, Mello, Vitória e Ferreira (1993) afirmam que a abordagem Ambientalista vê o adulto como o "principal agente e promotor do desenvolvimento infantil, aquele que ensina $\mathrm{e}$ dá à criança tudo aquilo que ela não tem, moldando seu comportamento, seu caráter e seus conhecimentos" (p. 29). Becker (2001) enfatiza que a postura empirista ou ambientalista revela-se claramente no ato de ensinar, como a aquisição de algo externo ao sujeito.

Refletindo sobre o estudo de Palacios (1990), particularmente sobre a classificação dos pais em modernos, tradicionais e paradoxais, e tomando por base vários fatores, entre eles as idéias interacionistas, inatistas e ambientalistas, poder-se-ia dizer que não há educadoras "modernas", uma vez que não existe predomínio da idéia interacionista. Um pequeno grupo de educadoras seria classificado como tradicional, pois suas idéias são inatistas. Das restantes, o grupo maior seria enquadrado como paradoxal, pois exprime crenças ambientalistas acompanhadas de inatistas. O nível educacional mais alto das educadoras, $2^{\circ}$ grau completo, não parece, nessa pesquisa, associado às crenças consideradas interacionistas, conforme mencionado por Palacios (1990), embora ele estivesse se referindo apenas ao nível universitário.

Outro aspecto que merece ser destacado é quem, na percepção das educadoras, são as pessoas significativas no desenvolvimento das crianças e em que direção essa influência é exercida, se positiva ou negativa. É interessante ressaltar que, embora as educadoras acreditem que a principal influência venha do meio ambiente, elas subestimam seu papel de promotoras do desenvolvimento dos bebês sob seus cuidados. Na verdade, elas percebem a si próprias como exercendo uma influência menor que as mães, apesar de passarem de quatro a dez horas diárias com a maioria dos bebês sob seus cuidados.

É interessante observar o julgamento das educadoras em relação a que pessoas influenciam o temperamento da criança: primordialmente a mãe, seguida do pai e com menor participação da educadora, avó/babá e irmãos. Parece que nesse julgamento está subjacente a crença de que o temperamento é inato e que as pessoas capazes de influenciar o bebê são aquelas ligadas a ele por fatores biológicos. Já em relação ao desempenho, outras pessoas foram incluídas como exercendo influência: mães, educadoras, outros bebês, irmãos, pais. Portanto, o desempenho dos bebês parece ser visto como passível de ser estimulado pelas pessoas que com eles convivem, nos diferentes ambientes que freqüentam.

As mães são citadas como exercendo grande influência no desenvolvimento de seus filhos; no entanto, só em pouco mais da metade do julgamento das educadoras elas foram consideradas como influenciando de forma positiva. Como interpretar esse dado? Por que elas são vistas como influenciando negativamente, tanto o temperamento quanto o desempenho dos filhos? Os resultados dos estudos de Haddad (1991), Martinez (1998) e Vitória (1997) muito se aproximam destes e as explicações realmente podem estar na re- 
Crenças de Educadoras de Creche

presentação do papel da função materna, que vem sendo construído ao longo do tempo, e da tentativa de autocompensação, ao perceberem que seu papel é pouco reconhecido e valorizado na sociedade. Elas percebem a si próprias como exercendo somente influências positivas, tanto no temperamento como no desempenho dos bebês. Outros estudos se fazem necessários para que possamos responder questões sobre como as educadoras vêem seu papel como "educadoras de creche" e como acham que são vistas pela sociedade.

A educadoras julgam o comportamento das avós e babás de forma mais negativa que a das mães. De acordo com elas, as avós e babás sempre prejudicam os bebês pelo excesso de cuidados dispensados a eles, tornando-os assim mais manhosos. É interessante ressaltar que a valorização da figura feminina no cuidado com os bebês, de modo geral, é vista de forma negativa, com exceção delas próprias e do pessoal técnico da creche, por estarem exercendo um papel profissional "Somos profissionais".

Já a figura paterna, embora julgada pelas educadoras como exercendo pouca influência no temperamento e desempenho dos bebês (em torno de 12\%), quase sempre o faz de forma positiva, dado também encontrado por Martinez (1998). Essa autora relata que o pai é visto pelas educadoras como aquele que tem facilidade em promover o processo de separação da criança, quando ela está sendo iniciada na escola, talvez porque ele já esteja mais acostumado a dividir o contato do filho com a esposa e outras socializadoras como a avó, a empregada e a babá. Outro aspecto a ser destacado é que, como em nossa sociedade o papel de cuidar do filho é atribuído à figura materna, o cuidado que ele tem com o filho pode estar sendo julgado pelas educadoras como algo além do papel que deveria exercer e, conseqüentemente, ser supervalorizado por elas. Dados semelhantes foram encontrados por Dessen e Braz (2000), que mostram claramente que as mulheres brasileiras de nível sócio-econômico baixo supervalorizam a participação do homem nas atividades domésticas e nos cuidados com os filhos.

O exemplo dado pelos irmãos ou outras crianças da creche é julgado como influenciando de forma positiva, principalmente no desempenho dos bebês, pois propiciam mais estimulação. Esse julgamento é coerente com a valorização de um ambiente rico, em que pelo menos uma criança interage com o bebê, ao contrário de um ambiente em que a criança fica só com adulto.

O conhecimento sobre as crenças das educadoras obtidos nesse estudo fornece indícios que podem subsidiar o planejamento de cursos de formação e educação continuada desses profissionais. Também sugere a importância de se estruturar um sistema de categorias que permita avaliar as crenças das educadoras como primeiro passo, prática essa essencial para a melhoria dos cursos e tomadas de decisões, pois, ao invés de se partir da visão sócio-interacionista a respeito de desenvolvimento, o essencial seria iniciar pela visão que as educadoras têm e, paulatinamente, ir trabalhando essa visão para depois transformá-la, se necessário. Nesse sentido, é importante estar alerta para o grau de complexidade ao se falar de crenças, uma vez que há possibilidade de coexistência de crenças opostas, em uma mesma pessoa, dependendo do que está sendo considerado. A ampliação dos estudos e a prática sistemática de avaliação das crenças das educadoras envolvidas no trabalho com bebês tornamse fundamentais, entre outros aspectos, para a melhoria do trabalho desse profissional, propiciando à criança condições de frequientar ambientes coletivos de alta qualidade.

\section{Referências}

Amorim, K. \& Rossetti-Ferreira, M.C. (1999). Creches com qualidade para a educação e o desenvolvimento integral da criança pequena. Psicologia, Ciência e Profissão, 19, 64-69.

Ariés, P. (1981). História social da criança e da família. (D. Flaksman, Trad.) Rio de Janeiro: Guanabara.

Bastos, A.C.C. (1991). Idéias sobre a criação de filhos: uma invenção cultural. Psico, 22, 63-87.

Becker, F. (2001). A epistemologia do professor ( $9^{\mathrm{a}}$ ed.). Petrópolis: Vozes.

D'Andrade, R.G. (1987). A folk model of mind. Em D. Holland \& N. Quinn (Orgs.), Cultural models in language and thought (pp. 112-148). New York: Cambridge University Press.

Dessen, M.A. \& Braz, M.P. (2000). A mulher e a rede social de apoio de famílias brasileiras por ocasião do nascimento de filhos [Resumo]. Em Sociedade Brasileira de Psicologia (Org.), XXX Reunião Anual de Psicologia. Resumos (p. 40). Ribeirão Preto: SBP.

Edwards, C.P., Gandini, L. \& Giovaninni, D. (1996). The constrasting developmental timetables of parents and preschool teachers in two cultural communities. Em S. Harkness \& C.M. Super (Orgs.), Parents ‘ cultural belief systems (pp. 270-288). New York: The Guilford Press.

Goodnow, J. (1992). Parents' ideas, childrens' ideas: Correspondence and divergence. Em I. E. Sigel, A.V. McGillicuddy-DeLisi \& J.J. Goodnow (Orgs.), Parental belief systems: The psychological consequences for children (pp. 293-317). Hillsdale, NJ: Erlbaum.

Goodnow, J. \& Collins, W.A. (1990). Development according to parents. The nature, sources, and consequences of parents ideas. Hove: Erlbaum.

Haddad, L. (1991). A creche em busca de identidade: perspectivas e conflitos na construção de um projeto educativo. São Paulo: Loyola.

Harkness, S. \& Super, C.M. (1996). Parents' cultural belief systems. Their origins, expressions, and consequences. New York: The Guilford Press.

Hess, R.D., Kashiwagi, K., Azuma, H., Price, G.G. \& Dickinson, W.P. (1980). Maternal expectations for mastery of developmental tasks in Japan and the United States. International Journal of Psychology, 15, 259-271.

Holloway, S.D. \& Reichhart-Erickson, M. (1989). Child-care quality, family structure, and maternal expectations: Relationship to preschool children's peer relations. Journal of Applied Developmental Psychology, 10, 281-298.

Lordelo, E.R. (1995). Ambiente de desenvolvimento humano: uma reflexão a partir do contexto da creche. Tese de Doutorado, Universidade de São Paulo, São Paulo. 
Lordelo, E.R., Fonseca, A.L. \& Araújo, M.L.V.B. (2000). Responsividade do ambiente de desenvolvimento: crenças e práticas como sistema cultural de criação de filhos. Psicologia: Reflexão e Crítica, 13, 73-80.

Martinez, C.M.S. (1998). Da família à escola: o ingresso da criança de 1 a 3 anos em novo contexto de socialização. Tese de Doutorado, Universidade Federal de São Carlos, São Carlos.

Miller, S.A. (1988). Parent's beliefs about children's cognitive development. Child Development, 59, 259-285.

Oliveira, Z.M. (Org.). (1995). A criança e seu desenvolvimento perspectivas para se discutir a educação infantil. São Paulo: Cortez.

Oliveira, Z.M., Mello, A. M., Vitória, T. \& Ferreira, M.C.R. (1993). Creches: crianças, faz de conta \& Cia. Petrópolis: Vozes.

Palacios, J. (1990). Parents' ideas about the development and education of their children. Answers to some questions. International Journal of Behavioral Development, 13, 137-155.

Pantoni, R.V., Teles, R., Mello, A.M. \& Rossetti-Ferreira, M.C. (1998). A formação nossa de cada dia. Em M.C. RossettiFerreira, A.M. Mello, T. Vitória, A. Gousen \& A.C. Chaguri (Orgs.), Os fazeres na educação infantil (pp. 26-31). São Paulo: Cortez.

Rosenthal, R. \& Jacobson, L. (1968a). Teacher's expectancies: Determinates of pupils' IQ gains. Psychological Reports, 19, 115-118.
Rosenthal, R. \& Jacobson, L. (1968b). Pigmalion in the classroom: Teacher expectations and pupils' intelectual development. New York: Renehart \& Winston.

Sigel, I.E., McGillicuddy-DeLisi, A.V. \& Goodnow, J.J. (Orgs.). (1992). Parental belief systems. The psychological consequences for children. Hillsdale, NJ: Erlbaum.

Sigolo, S.R.R.L. \& Biasoli-Alves, Z.M.M. (1998). Análise de dados de interação mãe-criança - construção de sistemas de categorias. Em G. Romanelli \& Z.M.M. Biasoli-Alves (Orgs.), Diálogos metodológicos sobre prática de pesquisa (pp. 87-118). Ribeirão Preto: Legis Summa.

Vasconcellos, V.M.R. \& Valsiner, J. (1995). Perspectiva coconstrutivista na Psicologia e na Educação. Porto Alegre: Artes Médicas.

Vigotsky, L.S. (1978). Mind in society: The development of higher psychological processes. Cambridge: Harvard University Press.

Vitória, T. (1997). Representações de educadoras sobre as mães e famílias das crianças da creche. Dissertação de Mestrado, Universidade de São Paulo, Ribeirão Preto.

Recebido em 13.12.2000

Primeira decisão editorial em 20.09. 2001

Versão final em 10.12.2001

Aceito em 31.01.2002 